\title{
ЦИФРОВАЯ ТРАНСФОРМАЦИЯ ЭКОНОМИКИ
}

\author{
(C) 2018 Удальцова Наталья Леонидовна \\ кандидат экономических наук, доцент департамента «Менеджмент» \\ Финансовый университет при Правительстве Российской Федерации \\ 125993, г. Москва, Ленинградский просп., 49 \\ E-mail: udaltsova.nl@yandex.ru
}

В статье рассмотрена концептуальная основа четвертой промышленной революции 4.0, ее ключевых технологий. Анализируются тенденции развития цифровых технологий в ряде стран. По прогнозам консалтинговой компании Mckinsey потенциальный эффект от коммерциализации цифровых технологий в российской экономике может достигать 19-34\% общего увеличения ВВП к 2025 году. Российская экономика располагает достаточными возможностями для осуществления цифровой трансформации с целью глобальной интеграции в мировое экономическое пространство. Реализация запланированной программы «Цифровая экономика Российской Федерации» сегодня нуждается в формировании общенациональной теории «цифровая экономика», признания и законодательного регулирования блокчейн-технологий и криптовалют, а также стимулирования образования цифровых компаний-платформ мирового масштаба.

Ключевые слова: цифровизация, трансформация, индустрия 4.0, технологии, цифровая экономика.

Стремительно развивающиеся цифровые технологии меняют привычные нам формы и методы ведения мировой хозяйственной жизни. Меняется не только отдельный бизнес, меняется и структура целых отраслей и секторов национальной экономики. Появляются новые направления и возможности для развития компаний, регионов и государств. Наступило невероятное время, когда раньше что-то было фантазией, сейчас реализуется как реальный проект. То, что сегодня мы с трудом представляем, уже завтра войдет в нашу обыденную жизнь. Такой процесс называется непрерывным инновационным процессом, основанным на технологиях четвертой промышленной революции.

Четвертая индустриальная революция, или как ее еще называют - Индустрия 4.0 - это переход на полностью автоматизированное цифровое производство, управляемое интеллектуальными системами в режиме реального времени в постоянном взаимодействии с внешней средой, выходящее за границы одного предприятия, с перспективой объединения в глобальную промышленную сеть вещей и услуг. Первая промышленная революция основывалась на механизации производства, изобретении парового двигателя и развитии железнодорожного транспорта. Заслуга второй промышленной революции - распространение электричества и развитие массового производства. Использование автоматизирование производства ста- ло возможно благодаря технологиям третьей промышленной революции, которые включают возможности информационных технологий и электроники. Именно благодаря ей производство стало массовым. Четвертая промышленная революция характеризуется слиянием технологий и стиранием граней между физическими, цифровыми и биологическими сферами.

Цифровая экономическая наука сформировала основание новой эпохи - информационной. Формирование Сети интернет, информативных технологий, стабильных каналов взаимосвязи, «облачных» технологий и числовых платформ, а кроме того, неоднократно увеличившийся размер данных, прибывающей с различных источников, гарантировали возникновение раскрытых информативных концепций и массовых индустриальных сеток. Это оказало преобразующее влияние на все секторы нынешней экономики и бизнеса и содействовало переводу индустриальной автоматизации в новую 4-ю ступень индустриализации.

Если говорить подробнее о технологиях программы «Индустрия-4.0», то следует говорить о реализации следующих ключевых направлений:

1. Промышленный Интернет Вещей - Industrial internet of things (сущность технологий заключается в специальном оборудовании и системе встроенных датчиков, которые объединены в единую сеть и подчинены в единую системе управления производством). 
2. Дополненная Реальность Augmented Reality (речь идет о технологиях, которые позволяют дополнить реальный существующий мир различными цифровыми и графическими данными в режиме реального времени, используя различные компьютерные возможности).

3. Большие Данные - BIG DATA и бизнес аналитика (технологии, позволяющие работать с большими массивами данных, оптимизировать информацию таким образом, что в конечном итоге позволяет улучшать качество производимой продукции, экономить ресурсы и повышать работоспособность оборудования).

4. «Облачные Технологии» - Cloud Computing (технологии дают возможность обрабатывать и хранить данные на удаленном доступе, а компьютерные ресурсы предоставляются пользователям как интернет-сервис).

5. Горизонтальная и Вертикальная Интеграция Систем (организация тесного взаимодействия как на различных уровнях внутри предприятия, так и между предприятиями- партнерами по производственному циклу).

6. Информационная Безопасность (защищенный доступ, надежная связь, полный контроль доступа к сетям управления).

7. Аддитивное Производство (освоение в промышленности аддитивных технологий, в том числе применение 3D-печати для прототипирования и производства отдельных деталей).

8. Цифровое Моделирование, являющееся одним из базовых направлений реализации программы «Индустрия-4.0», которое будет активно применяться в производственных процессах, в том числе путем использования актуальных данных, получаемых с помощью виртуальной модели окружающего физического мира.

Каждая страна по-своему демонстрирует успехи и подходы к созданию цифровой экономики. Пока абсолютного лидера в развитии всех аспектов цифровой экономики не наблюдается, хотя пионером промышленных технологий и родиной термина «Индустрия 4.0» является Германия. Определенных успехов достигла экономика США в развитии цифровых технологий в стране. Объем цифровой экономики в структуре ВВП достаточно высок и составляет 10,9\%, что в первую очередь связано с активным инвестированием частного и государственного секторов в цифровые технологии. Особенно быстро и эффективно развивается экономика Китая в сторону цифровизации. Несмотря на то, что экономика пока еще относится к развивающимся странам, но по доле цифровой экономики в ВВП сравнима с показателями США. Согласно оценкам Глобального ожидаемого института McKinsey в Китае появление до 22\% увеличения ВВП к 2025 г. может многим произойти за счет интернет-технологий.

Предполагается, что переход к цифровой экономике России будет одним из основных факторов роста ВВП. По прогнозам экспертов консалтинговой компании McKinsey потенциальный эффект для ВВП от цифровизациии российской экономик 2025 году оценивается в 4,1-8,9 трлн.руб., что составит 19-34\% общего увеличения ВВП. К приоритетным направлениям российской цифровизации относятся цифровые экосистемы, цифровые платформы, 3D-печать, углубленная аналитика больших массивов данных, интернет вещей и др.

Цифровая экономика - это часть реализуемого проекта «Индустрия-4.0». Она будет совершенствоваться за счет функционирования цифровых компаний. Функционирование подобных предприятий, укладывающихся в схему «Индустрия-4.0» предполагает цифровизацию и интеграцию научно-технических, производственных и бизнес-процессов по вертикали в пределах компании, начиная с исследования товаров и завершая созданием, логистикой и сервисом в ходе эксплуатации. Горизонтальная интеграция цифровой компании формируется в границах взаимодействия с поставщиками, покупателями и всеми партнерами, которые участвуют в цепочке создания стоимости продукции. Все действия контенируются, контролируются и управляются соответствующей цифровой платформой. Необходимо заметить, что цифровизация подразумевает смену аналоговых (физиологических) концепций сбора и обработки сведений научно-техническими режимами, которые предоставляют цифровой знак о своем состоянии. В широком значении - это процедура перенесения в цифровую сферу функций и бизнес-процессов, прежде выполнявшихся людьми и организациями.

Как упоминалось ранее, ключевым звеном осуществления процессов цифровой трансформации будет лежать в плоскости компании, которые должны отвечать следующим требованиям:

1. Компьютеризация, то есть снабжение средствами для цифрового управления. Все со- 
временное оборудование изначально рассчитано на цифровое управление, а оборудование, эксплуатируемое длительное время, должно быть соответствующим образом модернизировано.

2. Сетевое взаимодействие, то есть изолированные технологии должны быть объединены в общую среду, соответствующую требованиям бизнеса компании. Обычно для этой цели используют соединение по протоколу Internet Protocol (IP), образуя при этом Internet of Things. Сетевое взаимодействие позволяет объединить процедуры автоматического проектирования и производства CAD/CAM со средствами управления технологическими процессами Manufacturing Execution System (MES), организовать дистанционное обслуживание. Если усовершенствовать не новое, но работоспособное оборудование, то оно тоже может быть включено во взаимодействие.

3. Обозримость, то есть создание цифрового отображения или виртуального двойника предприятия.

4. Прозрачность, то есть связь цифрового отображения с аналитическими системами, шире известными как системы работы с большими данными.

5. Прогнозирование, для которого могут быть использованы адаптированные к производству технологии предиктивной аналитики.

6. Адаптивность, то есть способность к прогнозированию открывает возможность автоматизации функций, связанных с адаптацией бизнеса к изменяющимся внешним условиям.

Помимо перечисленных факторов, на эффективность перехода к цифровой экономике окажет влияние поведение и ментальность сотрудников предприятия, которые не в меньшей степени важны, что и технологии. Цифровая компания складывается в основном из двух вещей - готовность сотрудником к изменениям и свободное социальное взаимодействие на всех уровнях. Под готовностью к изменениям понимают: открытость к инновациям, постоянный профессиональный рост, приверженность к изменениям. Свободное социальное взаимодействие обеспечивается демократическим стилем руководства, возможностью открыто высказывать свои мнения, активным участием в эволюционном процессе.

Ключевым моментом в Индустрия 4.0 является создание инфраструктуры, имеющей в основе три типа интеграции: горизонтальная интеграция структурной модели бизнеса (value networks); сквозная цифровая интеграция производственных процессов (digital integration of engineering) по всей структурной модели бизнеса и вертикальная интеграция внутренней производственной цепочке предприятия (networked manufacturing). Трехступенчатая интеграция позволяет превратить всю национальную экономику в единую киберфизическую систему, объединенную государственным управлением. Киберфизические системы (Cyber-Physical System, CPS) - это системы, состоящие из различных природных объектов, искусственных подсистем и управляющих контроллеров, позволяющих представить такое образование как единое целое. В CPS обеспечивается тесная связь и координация между вычислительными и физическими ресурсами. Компьютеры осуществляют мониторинг и управление физическими процессами с использованием петли обратной связи, где то, что происходит в физических системах влияет на вычисления и наоборот. Сложность такого рода задач приводит к мысли о том, что речь идет о создании нового уровня автоматизации, где компьютеры интегрированы или встроены в те или иные физические устройства или системы. Речь идет о гармоничном сосуществовании двух типов моделей. С одной стороны - это традиционные инженерные модели (механические, строительные, электрические, биологические, химические, экономические и другие), а с другой - модели компьютерные.

В целях включения российской экономики в конкуренцию мирового экономического пространства была разработана Программа «Цифровая экономика Российской Федерации», утвержденная Правительством Российской Федерации, постановлением с 28 июля 2017 г. № 1632-p. Принятая программа опирается на «Стратегию формирования информативного сообщества Российской Федерации в 2017-2030 гг.» и отталкивается из того, что цифровая экономическая наука предполагает собою хозяйственную активность, основанную на цифровых технологиях. Цифровая трансформация существующих процессов в программе определена на трех уровнях, взаимодействие которых, собственно, и повлияет глобально на людей и общество в целом. Три уровня представлены следующими направлениями:

- технологическое развитие субъектов рын- 
ка и отраслей экономики (сферы деятельности), где исполняется горизонтальная интеграция между поставщиков и потребителей товаров, работ и услуг;

- развитие технологий и технологических платформ;

- формирование институциональной среды, задача которой создавать условия для успешного взаимодействия субъектов рынка. Институциональная среда включает в себя следующие элементы: нормативное регулирование, институты финансовой поддержки, информационная инфраструктура, развитие кадрового потенциала и др.

Фактически, программа «Цифровая экономика Российской Федерации» на сегодняшнем этапе сфокусирована на двух базовых направления. Первое направление будут формировать сами учреждения и компании как основное звено цифровой системы. Второе направление планируется реализовать через формирование инфраструктурной компоненты, которая будет обеспечивать непрерывный процесс цифровой трансформации российской экономики.

Реализацию проекта «Цифровая экономика Российской Федерации» допускается считать эффективной, в случае если к 2024 г. будут достигнуты все запланированные показатели, а именно:

- в России возникнут не менее 10 государственных фирм-лидеров. Это высокотехнологичные фирмы, которые разрабатывают «кросс-технологии» и управляют цифровыми платформами;

- в экономической системе будет функционировать как минимум 500 небольших и посредственных компаний, которые имеют отношения к области формирования цифровых технологий;

- количество выпускников согласно тенденциям информационно- телекоммуникационных технологий должно быть как минимум 120 тыс. человек в год, а число выпускников с компетенциями в сферы информативных технологий на среднем уровне не должно быть меньше 800 тыс. ежегодно;

- 40\% жителей обязаны иметь цифровые знания;

- количество реализованных планов в области числовой экономики объёмом 100 миллионов руб. должно быть никак не менее 30;

- количество отечественных учреждений, которые участвуют в осуществлении больших проектах в области цифровой экономики объёмом \$3 миллионов в приоритетных направленностях интернационального технологического партнерства - не меньше 10;

- что касается развития исследовательских компетенций и научно-технических заделов, то число реализованных планов обязано быть никак не меньше 30, число отечественных учреждений, участвующих в осуществлении больших планов в приоритетных направленностях интернационального учено-технологического партнерства, - 10;

- 97\% людей обретут допуск к широкополосному интернету с быстротой 100 Мбит/;

- во всех населенных пунктах, где живут более 1 миллионов человек, будет работать 5G;

- доля внутреннего сетевого трафика Рунета, маршрутизируемая через заграничные серверы, остановится на $5 \%$.

Кроме того, одной из ключевых целей проекта в документе называют возникновение не менее 10 высокотехнологичных компаний, трудящихся на массовом рынке и создающих около себе концепцию стартапов и исследовательских обществ, которые и станут гарантировать формирование цифровое экономики в дальнейшем.

В целях цифровой интеграции в мировое пространство и повышения конкурентоспособностей на основе ключевых технологий Индустрии 4.0 российская экономика нуждается в формировании общегосударственной теории цифровой экономики. Концепция цифровой трансформации представляется в развитии следующих направлений, которые и будут формировать общегосударственную парадигму «Цифровая экономика Российской Федерации»:

- признания и законодательного регулирования блокчейн-технологий, криптовалют и др.;

- стимулирования образования «компаний-платформ» мирового уровня (пилот - на основе Сбербанка);

- развитие государственной технологической инициативы - путевых карт внедрения новых технологий;

- развитие концепции статистических, национальных и открытых сведений, основанной на нынешних разработках, для целей увеличения производительности государственного управления;

- перевод концепций национальных и городских услуг в прогрессивные платформы с целью увеличения качества услуг и осуществле- 
нии персонифицированного расклада к любому гражданину и субъекту предпринимательской работы.

- новые технологические процессы, которые уже вводятся:

- развитие новых индустриальных технологий Индустрии 4.0 - интенсивная интеграция в фабричные процессы «киберфизических систем» (cps): 3d-технологии (печать), генная инженерия, интернет вещей, создание квантового процессора. Это лишь часть новых технологий, что радикально поменяют производство в кратчайший период;
Процесс цифровизации сегодня - это своеобразная технико-экономическая волна, которая пронизывает процессы от создания, контроля производства и продвижения продукта к потребителю и дальнейшему послепродажному обслуживанию. Россия занимает не худшие позиции, находясь в группе стран «последователей» технологий Индустрии 4.0. Очевидно, пока представляется заимствовать некий опыт в формировании модели электронной экономики со стран которые уже продвинулись в вопросах цифровизации, и уже сейчас задают технологический курс в мире.

\section{Библиографический список}

1. Восконян Е. Началась борьба за технологическое лидерство. Финансовая система тянется к потребителю// Эффективное антикризисное управление. 2018. № 2(6). С.34-37

2. Кривошапка И. Активное движение к цифре //Эффективное антикризисное управление. 2018. № 2(6). С.1621

3. Отчет «Цифровая Россия: новая реальность.Июль 2017 г.» URL: https://www.mckinsey.com/ /media/McKinsey/ Locations/Europe\%20and\%20Middle\%20East/Russia/Our\%20Insights/Digital\%20Russia/Digital-Russia-report. ashx (accessed 22.11.2018).

4. Доклад «Цифровая экономика: глобальные тренды и практика российского бизнеса». URL: https://imi.hsi. ru/pr2017 (accessed 22.11.2018).

5. Обзор «Индустрия 4.0»: создание цифрового предприятия PwC, URL: https://www.pwc.ru/ru/technology/ assets/global_industry-2016_rus.pdf (accessed 22.11.2018).

6. Всемирное исследование Digital IQ за 2017 год https://www.pwc.ru/ru/publications/digital-iq.html (22.09.2018)

7. Цифровая программа Российской Федерации», утвержденная распоряжением Правительства Российской Федерации от 28 июля 2017 г. № 1632-p, URL: http://static.government.ru/media/files/9gFM4FHj4PsB79I5v7yL VuPgu4bvR7M0.pdf

8. Указ Президента РФ от 9 мая 2017 г. № 203 «О Стратегии развития информационного общества в Российской Федерации на 2017-2030 годы»

9. Сагынбекова А.С. Цифровая экономика: понятие, перспективы, тенденции развития в России // Теория. Практика.Инновации». Апрель 2018.

10. Зозуля Д. М. Цифровизация российской экономики и Индустрия 4.0: вызовы и перспективы // Вопросы инновационной экономики. 2018. Том 8. № 1. С. 1-14-doi: 10.18334/vinec.8.1.38856

11. Любанова Т.П., Зозуля Д.М., Щерба Л.М., Олейникова Ю.А. Проблемы развития рыночной идеологии персонала российских промышленных предприятий в свете формирования цифровой экономики и «умного» общества // Экономика и предпринимательство. 2017. № 9-1(86-1). С. 847-853.

12. Стартапы кибербезопасности, которые смогли привлечь инвесторов // SPARK URL: https://spark.ru/ startup/innmind/blog/32038/startapi-kiberbezopasnosti-kotorie-smogli-privlech-investorov (дата обращения: 27.03.2018).

13. Как российские компании используют искусственный интеллект в бизнесе // eMagnat URL: http://emagnat. ru/kak-ispolzuyut-iskusstvennyj-intell.. (дата обращения: 27.03.2018).

14. Перпеляк А.И., Саломатина Е.В. Цифровая экономика: новые возможности для бизнеса // Научное сообщество студентов XXI столетия. Технические науки: сб. ст. по мат. LII междунар. студ. науч.-практ. конф. № $4(51)$. 